\title{
Light Weight Concrete with Full Replacement for Fine and Partial Replacement for Coarse Aggregate
}

\author{
Savithri S Karanth*, Ranjith N Reddy**, Sachin Shekhar**, Rohith Kumar**, \\ Syed Moshin** \\ *Associate Professor, Global Academy of Technology \\ Savithri_karanth@yahoo.co.in \\ **Students, Dept of Civil Engineering, Global Academy of Technology \\ Ranjithnreddy40@gmail.com, \\ sachinshekar.gc@gmail.com,rohit.cv0899@gmail.com,syed.snd584@gmail.com
}

\begin{abstract}
The normal concrete has a density of $2500 \mathrm{~kg} / \mathrm{m}^{3}$ which makes it difficult to handle at the time of construction and increasing the sectional dimensions of structural elements. The major contributions to the density of concrete is the high specific gravity of coarse and fine aggregate. In the present study, an attempt has been made to replace both coarse and fine aggregate by lighter weight material to achieve concrete of lighter density. Coarse aggregate was replaced by cinder in various percentages and fine aggregate was replaced by fly ash granules completely. M20 grade of concrete was designed as per IS10262-2009. Steel fibres at $1 \%$ by weight of cement was added to impart tensile strength. The cement was replaced by GGBS by $30 \%$ in weight to add strength. Compression, split tensile and flexural strength were conducted at 28 days. It was observed from the results that the reduction in strength after $40 \%$ replacement of coarse aggregate was nearly unchanged
\end{abstract}

Key words: Cinder, Flyash Granules, Coarse Aggregate, Fine Aggregate, Strength

\section{INTRODUCTION}

Light weight concrete has found its place in construction industry due to its better insulating properties, easy handling and faster rate of construction. Light weight concrete offers design flexibility, lowers the cost due to small sizes of structural members and less amount of steel needed [8]. Light weight concrete can be obtained by using light weight aggregates, air entraining, or by eliminating fine aggregates completely. The strength of light weight concrete is generally less than conventional concrete and cannot be adopted for heavy load bearing work. The concrete is said to be light weight if its density is less than $1800 \mathrm{~kg} / \mathrm{m}^{3}$. There are several industrial wastes which can be used as replacement for ingredients in manufacturing of light weight concrete.

Hanuman Sai Guptha [1] replaced coarse aggregate by cinder partially and fully in their investigation. The fine aggregate was replaced by cinder powder. Cubes, cylinders and beams were cast and tested for compression, split tensile and flexural strength. They concluded that granite aggregates can be replaced by cinder aggregate up to $40 \%$ without much loss of strength.

Dandu Chinna Narasimhudu [2] tried light weight concrete by replacing cement with flyash and silica fumes in addition to replacement of coarse aggregate by cinder. The studies concluded that the combination of 5\% silica fumes, $20 \%$ fly ash with up to $60 \%$ cinder show satisfactory results.

Dr. V. Bhaskar Desai and Mr. A. Sathyam [3] replaced the normal aggregate by cinder in 0,25 , 50,75 and $100 \%$. The various test results showed that compression, split tensile as well as flexural strength decrease continuously with increase in cinder content. However, up to $70 \%$ replacement, the values were within the acceptable strength limits.

N. Sivalinga Rao et al [4] explained the necessity of trial mixes in light weight concrete in the absence of accurate data of water absorption, moisture content etc. Their investigation projected $10 \%$ as optimum replacement of silica fume for cement with $40 \%$ cinder and $60 \%$ natural aggregates.

Manoj Kumar Dash [5]adopted several industrial by-products for replacement for natural aggregates. Strengths were compared .It was found that copper slag, fly ash replacement provide better strength to light weight concrete.

Obada Kayali[6] presented flashag as patented aggregate. The concrete made with flashag had atleast $25 \%$ more strength and $22 \%$ less weight. It also had at least $33 \%$ low drying shrinkage. 
Serkan Subasi[7]developed a light weight high strength concrete by adopting fly ash and high cement contents up to $450 \mathrm{~kg} / \mathrm{m}^{3}$.

\section{MATERIAL PROPERTIES}

Ordinary Portland cement, natural coarse aggregate of size $20 \mathrm{~mm}$ or less, cinder of $20 \mathrm{~mm}$ in size, fly ash granules of size below $4.75 \mathrm{~mm}$ and ordinary potable water for mixing concrete was used in the present investigation. Steel fibres at $1 \%$ by weight of cement was used to impart tensile strength. The materials properties are listed below.

Table 2.1 Cement

\begin{tabular}{|c|c|}
\hline Specific Gravity & 3.15 \\
\hline $\begin{array}{l}\text { Setting time } \\
\text { Initial } \\
\text { Final }\end{array}$ & $\begin{array}{l}\text { 95minutes } \\
\text { 200mins }\end{array}$ \\
\hline Normal consistency & $29 \%$ \\
\hline $\begin{array}{l}\text { 28days } \text { Compressive } \\
\text { strength }\end{array}$ & $57 \mathrm{~N} / \mathrm{mm} 2$ \\
\hline
\end{tabular}

Table 2.2 Coarse aggregate

\begin{tabular}{|l|l|}
\hline Specific Gravity & 2.79 \\
\hline Water absorption & $0.5 \%$ \\
\hline Fineness modulus & 4.9 \\
\hline
\end{tabular}

Table 2.3 Cinder

\begin{tabular}{|l|l|}
\hline Specific Gravity & 1.8 \\
\hline Water absorption & 3.5 \\
\hline Moisture Content & $0.5 \%$ \\
\hline Fineness Modulus & 4.1 \\
\hline
\end{tabular}

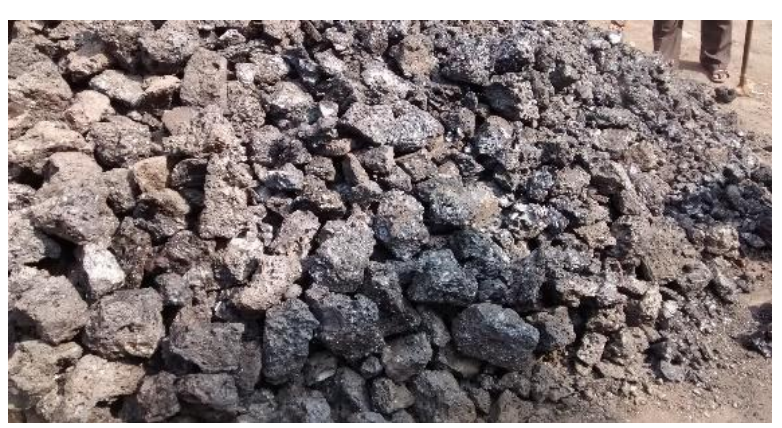

Fig 1 Cinder

Table 2.4 Fly ash granules

\begin{tabular}{|l|l|}
\hline Specific Gravity & 1.68 \\
\hline Water absorption & $18.5 \%$ \\
\hline Moisture Content & $3.1 \%$ \\
\hline Fineness Modulus & 2.9 \\
\hline
\end{tabular}

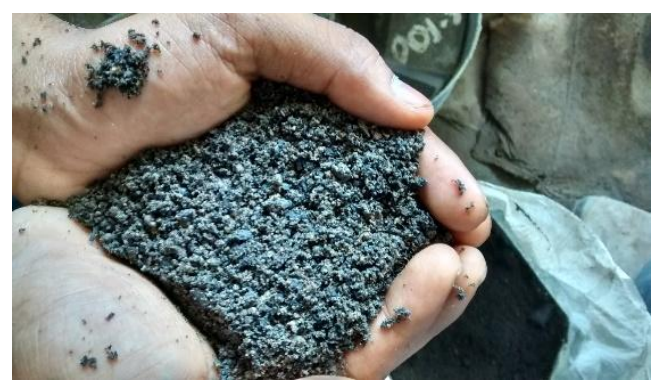

Fig 2 Fly Ash granules

Table 2.5 GGBS

\begin{tabular}{|l|l|}
\hline Specific Gravity & 2.8 \\
\hline
\end{tabular}

Table 2.6 Mix Design (M20 Grade of concrete) For $1 \mathrm{~m}^{3}$ of concrete

\begin{tabular}{|l|l|}
\hline Cement & $303 \mathrm{~kg}$ \\
\hline GGBS & $130 \mathrm{~kg}$ \\
\hline $\begin{array}{l}\text { Fine Aggregate(fly ash } \\
\text { Granules) }\end{array}$ & $408 \mathrm{~kg}$ \\
\hline Coarse Aggregate & $1110 \mathrm{Kg}$ \\
\hline Water & $216 \mathrm{lit}$ \\
\hline $\begin{array}{l}\text { Density of concrete at } \\
\text { design }\end{array}$ & $2167 \mathrm{~kg} / \mathrm{m}^{3}$ \\
\hline
\end{tabular}

Steel fibres of length $25 \mathrm{~mm}$ and diameter $0.45 \mathrm{~mm}$ are added at a ratio of $1 \%$ by weight of cement to add some tensile strength to concrete.

\section{Experimental Investigation}

Specimens were prepared with the obtained mix design. A workability of $100 \mathrm{~mm}$ slump was set as target in the mix design. Cubes, cylinders and beams were cast, air cured for 24 hours and water cured for 28 days. Specimens were taken out from water, dried and tested for compressive strength, split tensile strength and flexural strength. In the second stage, the specimens were prepared with addition of cinder as replacement for coarse aggregate at 20, 40, 60, 80 and $100 \%$. Specimens are tested for strength after air and water curing, Due to high water absorption of both cinder and fly ash granules; water demand was more to get the required workability as the percentage was varied. Aggregates were presoaked and drained before using them in the concrete. Suitable changes were made in water content to get the set workability values in terms of slump. Results were compared with standard specimens prepared without cinder. The results are tabulated and represented in graphs. 


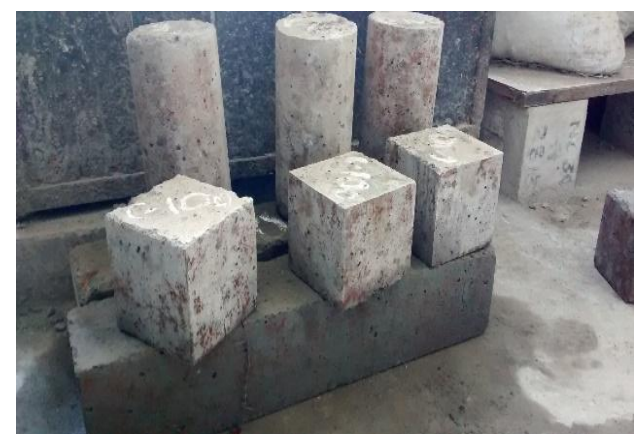

Fig 3 Specimens cubes, beams and cylinders

\section{RESULTS AND DISCUSSIONS}

As can be seen from the graph, the density of concrete changed from 2167 to $1774 \mathrm{Kg} / \mathrm{m}^{3}$ with various percentages of replacement of cinder. The density was less than normal concrete even with $100 \%$ natural aggregate since the fine aggregate was also replaced by low weight fly ash granules.

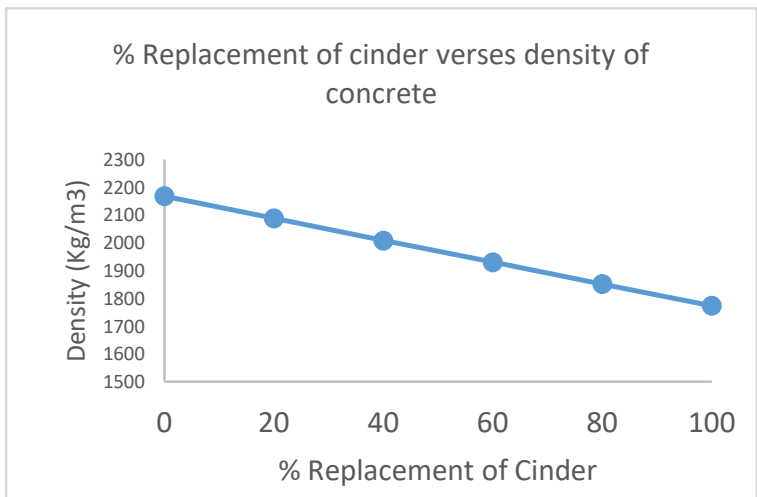

Fig 4 Density verses percentage of cinder

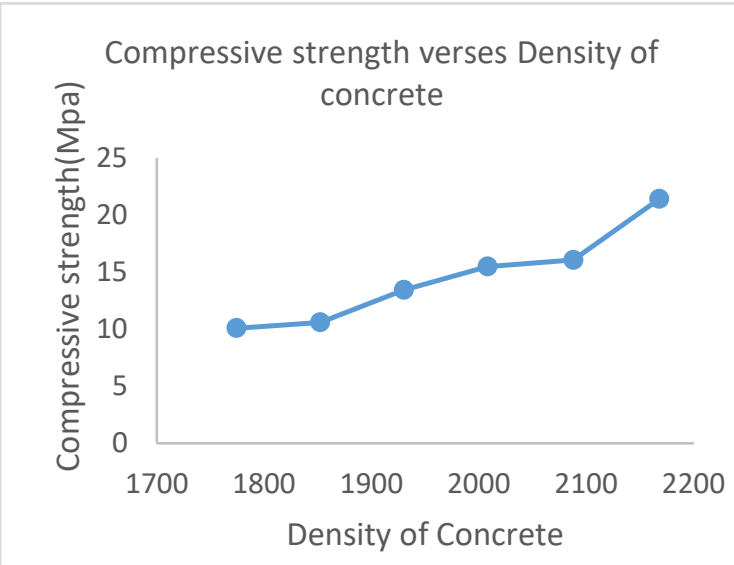

Fig 5 Variation of compressive strength with density of concrete

It is obvious that the light weight concrete has less strength than conventional concrete. It is observed from graphs that the strength reduced from 21.4 $\mathrm{MPa}$ to $10.09 \mathrm{MPa}$ with replacement of cinder. The strength loss was gradual except for the fact that there was a sudden drop of strength initially when $20 \%$ natural aggregate was replaced by cinders. The trend was same in split tensile and flexural strength also. The loss of strengths are shown in fig 6 and fig 7.The strength reduces with addition of cinder

progressively. The loss of strength appears to be gradual with increase in percentage of cinder. However, the drop in strength seems to be not affected much beyond $60 \%$ replacement of cinder.

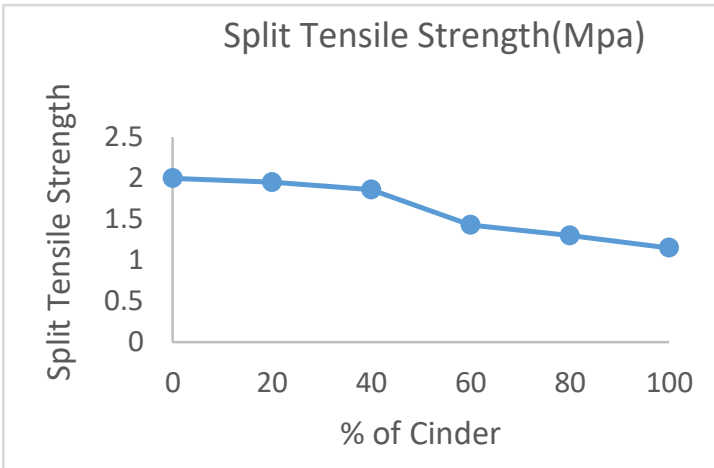

Fig 6 Variation of split tensile strength with percentage of cinders

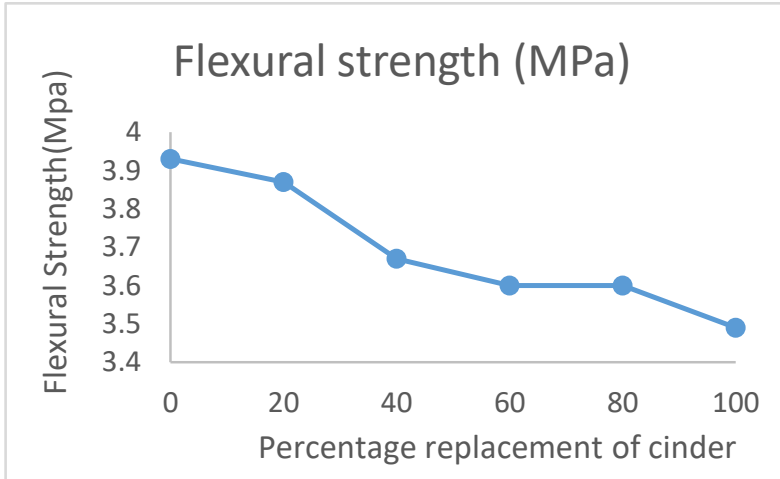

Fig 7 Variation of Flexural strength with percentage of cinders

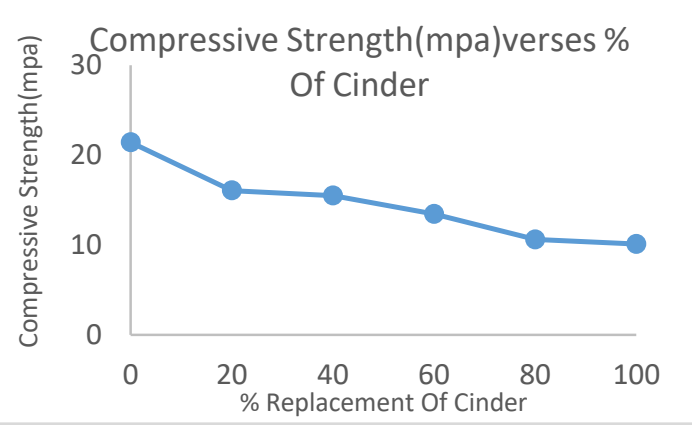




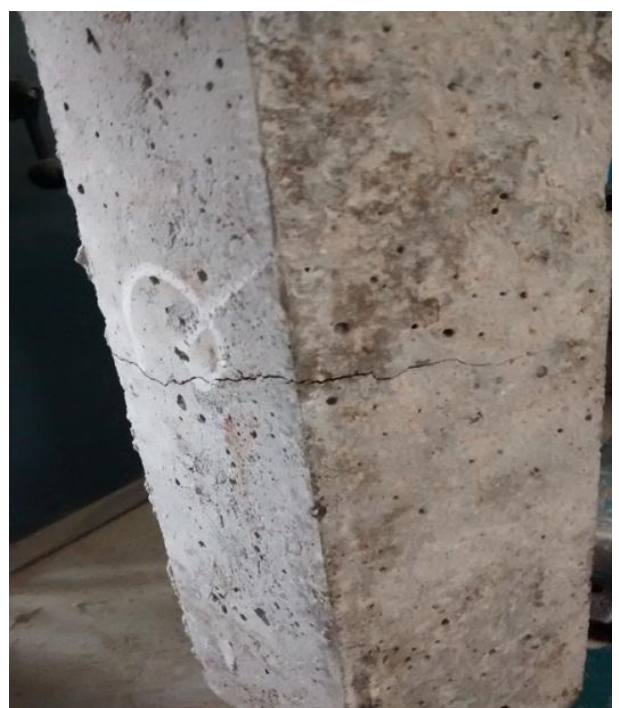

Fig 8 Beams showing crack before failure

Density is a direct indication of strength in concrete. This fact is proved in the present study also.

\section{CONCLUSIONS}

The following conclusions were drawn from the present experimental investigations

$>$ The fly ash granules can be used as replacement for river sand in the preparation of light weight concrete. The lower specific gravity of fly ash granules (1.68) reduces the density of concrete and makes it light weight.

$>$ The strength of concrete was found to be less by at least $25 \%$ due to the inclusion of fly ash granules when compared to the concrete made of river sand of same grade. Hence complete replacement of fine aggregate by fly ash may not be a good option.

$>$ The water absorption of fly ash granules was on higher side $(18.5 \%)$ compared to natural river sand. Additional water was needed to get the required workability. This could be a reason for increased porosity and reduced strength of concrete.

$>$ Cinder is a porous light weight material. Hence, the replacement of coarse aggregate by cinder would naturally make the concrete light weight. The density of concrete was found to reduce by $18.13 \%$ when coarse aggregate was replaced by cinder completely. The density of concrete was $1774 \mathrm{~kg} / \mathrm{m}^{3}$ with $100 \%$ cinder where as it was $2168 \mathrm{~kg} / \mathrm{m}^{3}$ with $100 \%$ natural coarse aggregate.

$>$ The mechanical strength of concrete reduced with the inclusion of cinder in concrete. However there was no drastic change in strength beyond $60 \%$ replacement. Major change in strength was observed only up to $60 \%$ replacement of coarse aggregate by cinder.
Similar trend was observed in density verses strength graphs also.

$>$ The total reduction in strength was $48 \%$, $42.41 \%$ and $11.2 \%$ in compression, split tensile and flexural strength with $100 \%$ replacement of coarse aggregate with cinder.

> There was no sudden failure of the specimen when cinder was introduced in higher percentages in flexure. Cracks were observed before failure.

Low density has several advantages compared to normal concreters. In the present investigation, low density concrete was obtained by replacing both coarse and fine aggregate by alternate light weight material. Though the strength reduced as also suggested by previous researchers, the goal of obtaining the light weight concrete was achieved.

\section{REFERENCES}

[1]. E.Hanuman Sai Gupta1, V.Giridhar Kumar2, Investigations on Properties of Light Weight Cinder Aggregate Concrete, International Journal of Engineering Research and Development e-ISSN: 2278067X, p-ISSN: 2278-800X, www.ijerd.com Volume 11, Issue 07 (July 2015), Page 5059

[2]. Dandu Chinna Narasimhudu,. Dr. P. Sri Chandana, , A Study on Properties of Light Weight Cinder Aggregate Concrete with Silica Fume and Fly Ash as Admixtures,IJMETMR,,Vol 2, issue 10 Page1097-1104,Oct 2015

[3]. Dr. V.Bhaskar Desai, Mr. A. Sathyam "Some Studies on Strength Properties of Light Weight Cinder Aggregate Concrete', International Journal of Scientific and Research Publications, Volume 4, Issue 2, February 2014 pg1-6

[4]. N. Sivalinga rao1, V. Bhaskar Desai2 and B.L.P.Swamy3, Structural Properties of Silica Fume Modified Light Weight Aggregate (Cinder) Concrete, IOSR Journal of Mechanical and Civil Engineering ISSN: 2278-1684, p-ISSN : 2320-334X Page 36-40

[5]. Manoj Kumar Dash, Sanjay kumar Patro,Ashoke Kumar Rathe,Sustainable use of industrial-waste as partial replacement of fine aggregate for preparation of concrete A review. International Journal of sustainable environment, Volume 5, Issue 2, December 2016, Pages 484-516

[6]. Obada Kayali,"'Flasag- New light weight Msaaterial for high strength and durable concrete" 2005 world of Coal 
Ash(WOCA), April 11-15 Lexington,

Kentucky,USA

[7]. Sercan Suba Duzee" The effects of using flyash on high strength light weight concrete produced with expanded clay aggregate"Turkey scientific Research and academic journals, Vol 4 page 275-288, April 2009 